\title{
İskemik kolitin nadir bir nedeni: Buerger's hastalığı
}

\section{A rare cause of ischemic colitis: Buerger's disease}

Ferdane SAPMAZ ${ }^{1}$, İsmail Hakkı KALKAN ${ }^{1}$, Sefa GÜLITER ${ }^{1}$, Pınar ATASOY ${ }^{2}$

Kırıkale Universitesi Tıp Fakültesi, ${ }^{1}$ Gastroenteroloji Bilim Dalı, ${ }^{2}$ Patoloji Ana Bilim Dalı, Kırıkale

Buerger's hastalığı ya da diğer adıyla tromboanjitis obliterans etkilenen damarlarda tromboz ve rekanalizasyonlarla giden bir hastalık olup, arter ve süperfisyal venlerde segmental okluzif ve multipl inflamatuvar lezyonlarla karakterizedir. Kolonik etkilenme çok nadir görülmektedir. Burada daha önce Buerger's hastalığı tanısı ile takip edilmekte olan hastada gelişen iskemik kolit tablosunu tartışmayı amaçladık.

Anahtar Kelimeler: Buerger's hastalığı, iskemik kolit, kolon, nadir

\section{GIIRIŞ}

Buerger's hastalığı diğer adıyla tromboanjitis obliterans özellikle orta ve küçük çapta arter ve venleri etkileyen nonaterosklerotik, inflamatuvar bir hastalıktır. Daha çok ekstremite arter ve venlerini etkilemektedir. Intestinal tutulum çok nadir olarak gözlenmektedir, genellikle de ince barsaktaki vasküler yapilar etkilenmektedir. Kolonik tutulum ise vaka sunumları halinde bildirilmiştir. Kliniğimize Buerger hastalığının nadir bir tutulum lokalizasyonuyla başvurması nedeniyle olgumuzu sunmayı uygun bulduk.

\section{OLGU SUNUMU}

Ellibeş yaşında erkek hasta, 2 gündür devam eden karın ağrısı ve kanlı dışkılama şikayetleri ile polikliniğimize başvurdu. Özgeçmiş sorgulamasında hastanın yaklaşık 10 ylldır tromboanjitis obliterans nedeni ile takip edildiği, yaklaşık 35 yıldır 1 paket/gün sigara içim öyküsü olduğu ve halen sigaraya devam ettiği , mevcut hastalığı nedeni ile sağ bacak ve sol el 2 parmağına ampütasyon uygulandığı öğrenildi.

Fizik muayenede, karın palpasyonunda tüm kadranlarda yaygın hassasiyet ve barsak seslerinde azalma, sağ bacak ampütasyonu, sol el 2 ve 3. proksimal falanksların ampüte olduğu gözlendi.

Hastanın laboratuar tetkiklerinde; Hb: 12,8 mg/dl, WBC: 7.500/L, Plt: 226.000/L, AST: 41 U/, ALT: 38 U/l, Albumin: 4,2 g/dl, T. bilirubin: 0,8 mg/dl, BUN: $15 \mathrm{mg} / \mathrm{dl}$, Kreatinin: $0.9 \mathrm{mg} / \mathrm{dl}, \mathrm{Na}: 140 \mathrm{mEq} / \mathrm{L}, \mathrm{K}: 4,1 \mathrm{mEq} / \mathrm{L}$ olarak saptandı. Hastaya karın ağrısı ve kanlı dışkılama yakınmaları nedeni ile öncelikle kolonoskopi yapılması planlandı ve gerçekleştiril-
Buerger's disease, or thromboangiitis obliterans, is characterized by occlusive segmental and often multiple inflammatory lesions of arteries and superficial veins with thrombosis and recanalization of the affected vessels. Involvement of the colon is extremely rare. Herein, we present a case of colon ischemia in a patient diagnosed previously as Buerger's disease.

Keywords: Ischemic colitis, Buerger's disease, thromboangiitis obliterans

di. Kolonoskopide sigmoid kolon proksimalinde yaklaşık 5 cm'lik bir segmentteki mukozada ödem, hiperemi, tüm lümeni çepeçevre saran ülserasyon alanı, mukus ve eksuda izlendi, bu bölgeden biyopsiler alındı (Resim 1). Bu segment dışındaki tüm kolon mukozası ve terminal ileum normal görünümdeydi. Hastanın tüm batın bilgisayarlı tomografisi çekildi, ancak inferior mezenterik arter görüntülenemedi. Mezenterik anjiografi uygulandı, ancak vizualizasyon sağlanamadı. Kolonoskopik biyopsi sonucunda iskemik kolit ile uyumlu olarak,

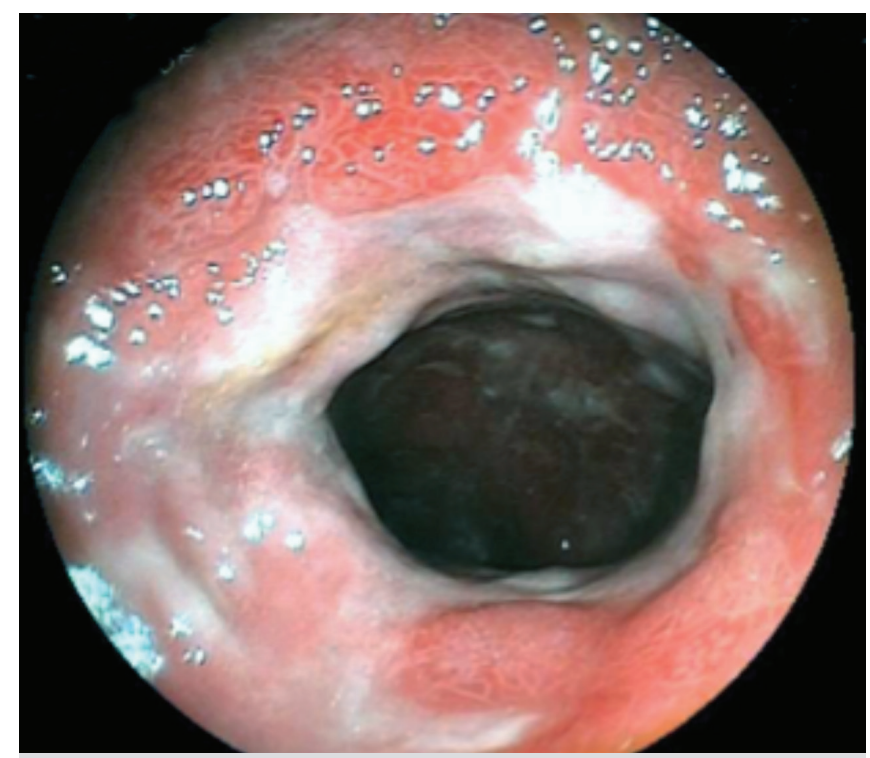

Resim 1. Buerger's hastalığına bağlı kolonik etkilenme 
yüzey epitelinde atrofi, konjesyon ve fibrotik lamina propriadaki kriptlerin epitelinde müsin kaybı izlendi.

Endoskopi ve histopatoloji bulguları ve Buerger hastalığı hikayesi nedeniyle hastada Buerger hastalığına bağlı iskemik kolit düşünülerek intravenöz hidrasyon+ enoksaparin 6000 IU 2xl+ iloprost 0,5 ng/kg/dk'dan başlandı. Iloprost dozu 3 . günde 2 ng/kg/dk'a çıkıldı. Yaklaşık 1 hafta sonra yapılan sigmoidoskopisinde belirgin iyileşme, şikayetlerinde tama yakın gerileme tarifleyen hasta sigarayı biraktı, mevcut durumu ile polikliniğimizde izlenmeye devam ediliyor.

\section{TARTIŞMA}

Buerger's hastalığı, özellikle genç, sigara içici erkeklerin hastalığı olarak gözlenmektedir. Bu hastalıkta genellikle ekstremitelerin orta ve küçük çaplı arter ve venleri etkilenmektedir. Ana semptom etkilenen bölgede ağrıdır. Hasta bölgede kan akıminda progresif bir azalma ile birlikte gangrene giden bir süreç yaşanabilmektedir.

Tromboanjitis obliterans tanısı klinik semptomlar ışığında konabilmekte ve 5 kriter baz alınmaktadır; sigara içim öyküsü, 50 yaşından önce başlangıç, infrapopliteal arteriyel okluzif hastalık, flebitis migrans ve sigara dışında diğer aterosklerotik risk faktörlerinin yokluğu.

Hastalığın tanısında spesifik bir laboratuvar tetkiki bulunmamaktadır. Biyopsi ve doku örnekleri hastalığın tanısının konmasında çok az yardımcı olabilmektedir. Çünkü nadir biyopside hastalık için spesifik faz ve bulgulara rastlanmaktadır (1). Hastalığın akut fazında damar duvarının tüm katlarında akut bir inflamasyon söz konusu iken, subakut fazda arter ve venlerde ilerleyici ve okluzif bir trombüs organizasyonu, kronik fazda ise rekanalizasyon, medial ve adventisyal fibrozis gerçekleşmektedir (2). Benzer histopatolojik bulgular diğer otoimmün hastalıklarda da görülebileceğinden, ayırıcı tanının yapılması önem taşımaktadır.

Geniş arteriyel oklüzyon ve sonucunda ortaya çıkan tirbüşon şeklinde kollateral damarlar spesifik anjiografik bulgu olarak karşımıza çıkmaktadır, ancak bu bulgu patognomonik değildir.

Buerger's hastalığında gastrointestinal etkilenme çok çok nadir olarak gözlenmiştir. Bugüne kadar 29 olgunun Buerger's hastalığına bağlı gastrointestinal semptom nedeni ile değerlendirildiği bildirilmektedir (3). Gastrointestinal etkilenme herhangi bir dönemde gerçekleşebilmekle birlikte, genellikle hastalığın ilerleyen dönemlerinde gözlenmektedir. Mezenter damarların etkilenmesi, ciddi periferal vasküler hasar olduktan sonra meydana gelmektedir. Gastrik, kolonik, çölyak ve mezenterik arteler veya bunların daha küçük dalları etkilenebilmektedir.

Bugüne kadar bizim vakamızda olduğu gibi kolonik Buerger's hastalığı olan sadece 6 olgu bildirilmiş ve bunlardan sadece 3'ünde medikal tedavi ile iyileşme sağlanabilmiştir (4).

Özetle, Buerger's hastalığında gastrointestinal etkilenmenin tanısı oldukça zor konabilmekte ve kötü prognozla sonuçlanabilmektedir. Özellikle daha önce tromboanjitis obliterans tanısı bulunan hastalarda gastrointestinal semptom varlığında erken tanının intestinal obstrüksiyon ve gangren formasyonunu önlemede ne kadar önemli olduğu unutulmamalıdır.

\section{KAYNAKLAR}

1. Magalhaes Ede P, Trevisan M, Mochizuki M, et al. Intestinal ischemia as a single manifestation of thromboangiitis obliterans: a case report. Angiology 2005; 56: 789-92.

2. Kobayashi M, Nishikimi N, Komori K. Current pathological and clinical aspects of Buerger's disease in Japan. Ann Vasc Surg 2006; 20: 148-56.

3. Cordobès Gual J, Riera Vázquez R, Merino Mairal O, et al. Buerger's disease with intestinal ischemic involvement. An Med Interna 2005; 22: 235-7.

4. Kobayashi M, Kurose K, Kobata T, et al. Ischemic intestinal involvement in a patient with Buerger disease: case report and literature review. J Vasc Surg 2003; 38: 170-4. 